\title{
Analysis on Creep Properties of Aquiferous Loess under a High Confining Pressure
}

\author{
Renhong Ding ${ }^{1}$, Hao Tang ${ }^{2, *}$, Zhao Duan², Yanqing Zhang ${ }^{3}$ and Hongjun Jing ${ }^{3}$ \\ ${ }^{1}$ Ankang City Transportation Comprehensive Law Enforcement Detachment, Ankang 712500, China \\ ${ }^{2}$ College of Geology and Environment, Xi'an University of Science and Technology, Xi'an 710054, China \\ ${ }^{3}$ College of Architecture and Civil Engineering, Xi'an University of Science and Technology, Xi'an 710054, China
}

Received 23 January 2021; Accepted 17 June 2021

\begin{abstract}
Creep properties of loess are related with time-dependent deformation of loess slope. In particular, creep properties of loess at slope foot in the high stress state vary significantly when meeting water, which influence the long-term stability of slope significantly. Therefore, how do creep properties of aquiferous loess under a high confining pressure change is a problem that has to be solved urgently. In this study, creep properties of loess with different moisture contents at a slope foot in Liquan County, Xianyang City, Shaanxi Province, China under a high confining pressure were analyzed through a triaxial creep test. A new nonlinear viscous-plastic model was constructed based on the fitting analogy technology of accelerated creeping segment of loess with different moisture contents and used to improve the four-element model of loess. Results demonstrate that when the deviatoric stress is smaller than the critical stress threshold, axial strain of loess is manifested as the pattern of instantaneous deformation, decelerated creeping and deformation constant. When deviatoric stress is larger than critical stress threshold, axial strain of loess is manifested as the pattern of instantaneous deformation, decelerated creeping and steady creep or instantaneous deformation and accelerated deformation. With the increase of moisture content under a high confining pressure, the creep deformation ability of loess is enhanced. The elastic deformation and viscoelastic strain parameters of loess present negative exponential reduction with the increase of moisture content. The improved four-element model of loess can describe creep properties of aquiferous loess under a high confining pressure well. The study results can provide some theoretical references to analyze time-dependent deformation of loess slope when meeting water.
\end{abstract}

Keywords: Moisture content, Loess, Creep properties, Constitutive model

\section{Introduction}

With the economic development and expansion of range of human activity in different regions, more and more infrastructural projects have been constructed, which brings more and more engineering geological problems of loess foundation and loess slope, such as loess foundation settlement and loess slope instability. Essentially, many engineering geological problems caused by the interaction between loess and engineering construction are related with long-term deformation of loess. It is necessary to reasonably evaluate stress state at the position where loess locates at and propose reasonable creep constitutive model of loess.

According to the classical elastic-plastic theory, stressstrain state in soil masses is determined by the external loading mode, loads and physical and mechanical properties of loess. Differences in stress state or soil properties might cause different soil deformations. Loess is a porous Quaternary sediment with weak cementation. It has complicated structures due to the particle composition, arrangement and combination of soil particles and interaction force among particles. Moreover, deformation of loess slope is often closely related with time. To describe deformation of loess with time, many scholars have been seeking a constitutive model to describe loess creeping. Currently, the constitutive model of soil creeping mainly includes empirical model [1-2], element combination model
[3-4] and yield surface model [5-6]. The empirical model of soil creeping is a functional relation which is set up based on the creeping test of soils, which is also called empirical equation. In most cases, the empirical model is only applicable to some specific soil mass and it is difficult to be promoted to other soil types, thus resulting in some limitations. Element model is a model that combines basic elements like elastic elements, viscous elements and plastic model elements in series or parallel to simulate creeping behavior of soil mass. The element combination model has been widely applied in practical engineering for the clear concept, simple image and explicit physical significance which are determined by the unique element combination mode. The yield surface model is a three-dimensional model that combines yield surface criteria, maxim of relevance and hardening laws to study creeping laws of soil mass. The single yield surface model can reflect the variation law of creeping of soil mass along any stress paths, but it cannot interpret the reduction of intensity with time. Although the double yield surface model can solve shortages of single yield surface, its construction process is relatively complicated.

As a heterogeneous and discontinuous soil mass, loess has strong nonlinear characteristics. Hence, the constitutive model which is used to express the stress and strain of loess shall be able to reflect its nonlinear characteristics [7]. The constitutive expression of loess is the core of studies on loess and the constitutive model which involves creeping changes with time is the key to study time-dependent stress and strain. The properties of loess are related with many 
factors, such as moisture content, confining pressure, initial defect and compaction degree. Among them, creep properties of loess are mostly sensitive to water. As a result, studying deformation characteristics of loess under a high confining pressure and different moisture contents is of important significance to propose a reasonable creep constitutive model of loess and analyze stability of loess slope.

On this basis, a triaxial creep test of loess under a high confining pressure and different moisture contents was carried out and the nonlinear viscous element was improved by fitting and analogy. Moreover, a nonlinear creep model with considerations to influences of moisture content was constructed. This study aims to lay foundations for further analyze the deformation characteristics of loess slope.

\section{State of the art}

Slope instability is often related with creep deformation of rock-earth mass. It takes a long time to develop creep, which brings difficulties to field monitoring. The creep test of soil is the most intuitive and the most important mean to study creep properties of soil mass and it is convenient for people to understand deformation characteristics of soil mass at different time.

With great progresses in creep test apparatus, studies on creep properties of soil mass under uniaxial compression condition and triaxial compression condition have accumulated experiences to understand creep behaviors of soil mass comprehensively. Wang et al. [8] discussed drainage creep properties of saturated mucky clay, silt and fine sands through a solidified triaxial drainage creep test and fit the test data by using Merchant and Burgers creep model. Results demonstrated that creep coefficients of all three soil masses were closely related with stress level. They all increased with the increase of stress level, but were less related with confining pressure. When stress level is $\mathrm{S}<0.8$, both creep models can achieve relatively good fitting effects. However, neither of them can describe creep properties of soil masses when $\mathrm{S}>0.8$. Sun et al. [9] carried out a largescaled triaxial creep test on typical creep-type landslide soil and discussed creep laws of slip soils under different confining pressures and stress levels. Meanwhile, they further determined the difference between long-term intensity and conventional intensity of slip soil by using the isochronal curve method. Results demonstrated that absolute creep volume and deformation rate in the stable creep stage of slip soil is positively related with axial stress, but the duration in the attenuation creep stage basically presented a linear growth with the increase of shear stress level. However, deformation magnitude and durations of different stages in the test were significantly different from field results. Kamoun et al. [10] discussed creep properties of clay through a triaxial compression test. Results showed that shear deformation of samples increased with the increase of initial saturation and stress level. In the test, samples shrank firstly and then swelled. Moreover, they showed great shrinkage distortion under a high stress level and initial saturation. Research results provide an idea to realize numerical computation of creep properties of clay. Liu et al. [11] carried out a creep test under multiple loading levels by using a triaxial apparatus, in which creep deformation, creep rate and long-term intensity of soft clay under the true triaxial stress path were discussed. Results showed that creep deformation and creep rate of soft soil increase with the increase of principle stress, and the axial deformation was higher than transverse deformation. However, influences of moisture content on creep properties of materials were ignored. Xue et al. [12] studied anti-shear strength and creep properties of red clay through a triaxial solidification drainage test and a creep test. They found that failure mode of red clay samples after creep was a drum-like parabola and had a preset shearing surface. However, the confining pressure in the test was small.

Creep constitutive model of soils is a functional relation that reflects variation laws of soil stress-strain with time based on the creep test. It can provide a quantitative characterization of creep properties of soil mass. studying creep constitutive model of soils is the most basic and the most important component in theoretical study of soil creep. Based on creep deformation laws of coarse aggregates, the empirical model of the creep index of coarse aggregates and relevant expression of final creep are proposed. A viscoelastoplastic constitutive model of was constructed in the constitutive model framework of coupling crushing and friction energy consumption. Meanwhile, deformation characteristics of coarse aggregate highfill body were analyzed through a numerical simulation. This model can simulate softening/hardening and dilatation/shear contraction characteristics of medium-sized coarse aggregate in the shearing process and predict the deformation development law in the creep stage. Guo et al. [14] carried out a series of laboratory solidification creep tests of loess by using a reconstructed plane creep instrument. They found that the plane creep volume of loess was high under a high shearing force, a high moisture content and a low solidification pressure. Based on tests, a model which is suitable for plane creep of loess was established. This model is characteristic of high precision, few parameters and easy availability. It can simulate creep properties of loess under plane strain state. Based on the theory of plasticity and critical state of boundary surface, Shahbodagh et al. [15] proposed a viscoplasticity model with considerations to creep of soils in the viscoplasticity framework and carried out drainage and non-drainage creep tests to verify accuracy of the model. The proposed model could describe viscoplastic strain accumulation under loading and unloading processes as well as the creep deformation of overconsolidated soils. Tafili et al. [16] proposed a plastic model that can describe deformation characteristics of clay with time. They also carried out drainage and non-drainage triaxial tests of different types of clay through numerical simulations, which achieved good outcomes. This model performed well in describing mechanical behaviors of natural and remodeling clays, especially with considerations to time and strain rate effect. Based on previous research results, Gras et al. [17] proposed a three-dimensional constitutive model which considers creep, anisotropism and structure of natural clay. However, parameters of this model were difficult to be gained. Based on the critical state soil mechanical framework, Islam et al. [18] developed an elastic-viscoplastic constitutive model with considerations to creep effect of isotropic clay by using the nonlinear creep function. However, this model failed to meet the consistency condition since it used any overstress function. Based on the triaxial compression test results of rocks, Jin et al [19] connected Hook and Kelvin in series and proposed a nonlinear creep model of rocks based on strain softening index. Results showed that rock had viscoplastic softening in the accelerated creep stage, which could control the increase of viscoplastic strain rate. This model was applicable to 
simulate the accelerate creep phenomenon of rocks with plastic softening characteristics and had easy-available parameters. The delayed failure of slope usually is related with the rising underground water level, excavation at slope foot and viscosity phenomenon of soils. By combining the structural degeneration and viscous effect of cohesiveless soil, Kavvadas et al. [20] proposed a plasticity model of soil mass with considerations to time effect and studied creep properties of slope under the drainage conditions by using numerical simulation. This model can predict creep failure of soil mass under drainage and non-drainage conditions, but its parameters are relatively complicated. Based on the triaxial creep test results, Oliveira et al. [21] constructed a creep constitutive model of soft soils which considered influences of preloading by combining the Cambridge model and creep laws, and predicted the long-term deformation characteristics of soft soil embankment under the preloading effect. However, this model has some limitations in predicting the effective stress path. Yuan et al. [22] carried out a series of triaxial solidification creep tests of soft soils and proposed a method to determine parameters for Merchant model which is related with confining pressure and stress levels. On one hand, they disclosed that parameters present linear reductions with the increase of stress level under the same confining pressure. On the other hand, they constructed a three-dimensional nonlinear viscoelastic creep constitutive model of soft soil that reflects time effect, which can effectively simulate the nonlinear development process of embankment settlement in different construction stages and the variation laws of settling rate. However, influences of environmental factors on creep properties of materials were ignored.

To address shortages of existing studies, a triaxial creep test based on loess at a slope foot in Liquan County, Xianyang City, Shaanxi Province, China was carried out to study creep behaviors of loess under different moisture contents and a high confining pressure. Based on the test results, a new nonlinear viscoplastic model was constructed to describe creep properties of loess and it was expected to expand knowledge on creep of loess. It provides some theoretical bases to analyze stability of loess slope.

The reminder of this study is organized as follows. Section 3 describes the triaxial creep test design of loess and introduces the four-element model of loess. Section 4 analyzes and discusses test results and constructs an improved four-element model of loess. Section 5 summarizes the study and provides the relevant conclusions.

\section{Methodology}

\subsection{Test apparatus and materials}

This triaxial creep test of loess used the SLB-1A triaxial rheological tester of soil mass (Fig. 1). Natural loess $\left(Q_{2}\right)$ from the collapsed slope foot in Liquan County, Xianyang City, Shaanxi Province, China was collected as the samples. The intact loess is tawny with columnar jointing and low natural moisture rate. Soil blocks which are collected in field were prepared into $39.1 \mathrm{~mm}$ (diameter) $* 80 \mathrm{~mm}$ (height) cylinder species in laboratory.

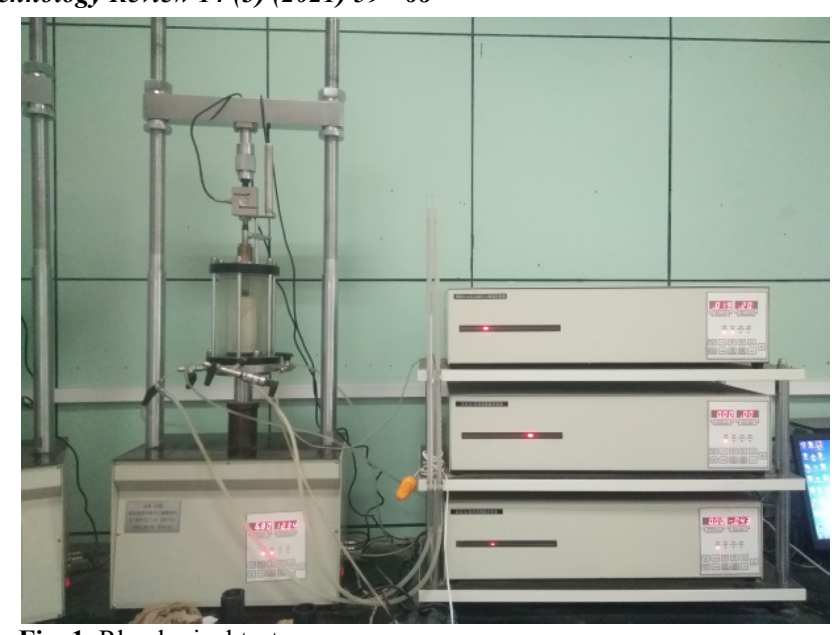

Fig. 1. Rheological tester

\subsection{Test design}

Before the creep test, a triaxial solidification non-drainage test was carried out to loess samples to test the breaking strength. Multi-stage loading was applied in the creep test and the confining pressure was set $250 \mathrm{kPa}$.

According to the test objective, all specimens had moistened artificially by water film migration method, thus getting loess samples $\left(Q_{2}\right)$ with four different moisture contents $(8 \%, 13 \%, 17 \%$ and $23 \%)$.

Before the test, the number of loading stages and loading increments were preset according to breaking strengths of loess in the triaxial solidification non-drainage test under the same confining pressure. In the test, each loading stage lasted for $12 \mathrm{~h}$ and the next loading stage started after deformation of specimens is stabilized. This was repeated until the final failure of specimens.

\subsection{Four-element model of loess}

Creep of loess under the compression is mainly manifested by instantaneous elasticity, viscosity, viscoelasticity and viscoplasticity. Classical element theory realizes the goal of describing creep properties of materials by constructing a model that connects different mechanical representative elements in series and parallel.

Instantaneous elasticity of materials can be reflected by single spring based on the element theory. Viscosity of materials is simulated and described by using the viscous element (dashpot). However, a simple ideal viscous element (dashpot) is not satisfying in reflecting the nonlinear viscosity of rock and earth and shows no obvious physical significance. Ideal solid is the mechanical description object of traditional spring component, while ideal fluid is the mechanical description object of dashpot element. The constitutive equation above two elements is rewritten through mathematics (Eq. (1)). The constitutive equations of the spring element and the dashpot element show that stress is the differentiation functions of different-order derivation of strains. Moreover, orders are at the extreme states of 0 and 1 due to the represented ideal elements.

$\left\{\begin{array}{l}\sigma(t)=E \frac{d^{0} \varepsilon(t)}{d t^{0}} \\ \sigma(t)=\eta \frac{d^{1} \varepsilon(t)}{d t^{1}}\end{array}\right.$

Yin et al. [23-24] introduced the fractional calculus into the studies on rheological element, a soft-matter element 
based on fractional calculus was proposed (Fig. 2). The constitutive equation is shown in Eq. (2).

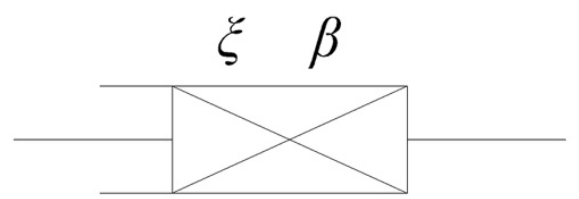

Fig. 2. Soft-matter element

$$
\sigma(t)=\xi d^{\beta} \varepsilon(t) / d t^{\beta} \quad(0 \leq \beta \leq 1)
$$

where $\xi$ and $\beta$ are material constants. The former one represents the viscosity-like coefficient of the soft-matter element and its physical dimension is [stress time ${ }^{\beta}$ ]. The later one is the number of orders of the differential equation of the soft-matter element.

Based on the Riemannn-Liouville fractional calculus operatory theory, Eq. (2) can solve the creep equation of the soft-matter element, as show in Eq. (3):

$$
\varepsilon(t)=\frac{\sigma}{\xi} \bullet \frac{t^{\beta}}{\Gamma(1+\beta)} \quad 0 \leq \beta \leq 1
$$

where $\Gamma(x)$ is the Gamma function and its value is calculated according to Eq. (4):

$$
\Gamma(x)=\int_{0}^{\infty} e^{-t} t^{x-1} d t \quad(\operatorname{Re}(x)>0)
$$

It can be seen from the comparison between Eq. (1) and Eq. (2) that the basic structure of constitutive equation of the soft-matter element is similar with a spring element and dashpot element. The order ranges in the interval of [0 1], which can be understood as that the described mechanical object is the rock-earth material media between the ideal solid and ideal fluid. After operation verifications of many scholars [25-29], the soft-matter element has good effect in reflecting nonlinear viscous properties of rock-earth materials.

For viscoplastic properties of loess, the model which is formed by parallel connection of ideal plastic element and dashpot element based on the element theory basically reflect viscoplastic characteristics of elements.

According to above tests on creep properties of loess in different stages, elasticity, viscoelasticity and viscoplasticity

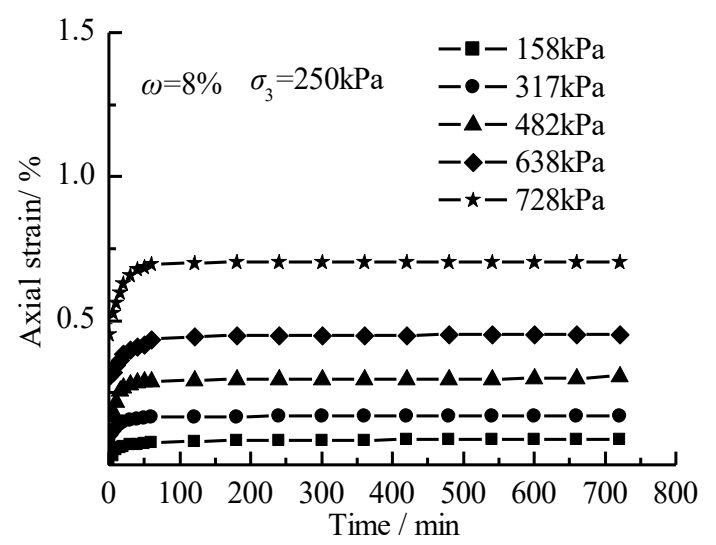

(a) $\omega=8 \%$

Fig. 4. Strain-time curves of loess under different deviatoric stresses of loess can be simulated through series connection of the spring component, soft-matter element and viscoplasticity model. The model is composed of four elements and its structure is shown in Fig. 3.

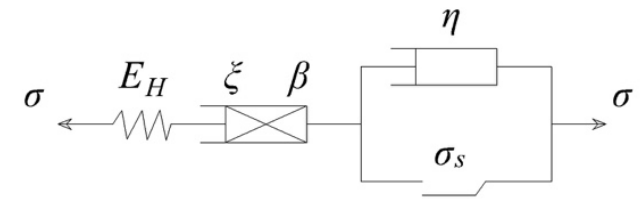

Fig. 3. Four-element model of loess

It can be seen from Fig. 3 that according to the connection characteristics of the four-element model, it can get Eq. (5):

$\left\{\begin{array}{l}\sigma_{1}=\sigma_{2}=\sigma_{3}=\sigma \\ \varepsilon_{1}+\varepsilon_{2}+\varepsilon_{3}=\varepsilon \\ \sigma_{1}=E_{H} \varepsilon_{1} \\ \sigma_{2}=\xi \frac{d^{\beta} \varepsilon_{2}}{d t^{\beta}} \\ \sigma_{3}=\eta \frac{d \varepsilon_{3}}{d t}+\sigma_{s}\end{array}\right.$

According to series connection features of the model, the creep equations of different units in the series are solved one by one and then added to get the creep equation of the fourelement model of loess, as shown in Eq. (6):

$$
\begin{cases}\varepsilon=\frac{\sigma}{E_{H}}+\frac{\sigma}{\xi} \bullet \frac{t^{\beta}}{\Gamma(1+\beta)} \quad \sigma<\sigma_{s} & 0<\beta<1 \\ \varepsilon=\frac{\sigma}{E_{H}}+\frac{\sigma}{\xi} \bullet \frac{t^{\beta}}{\Gamma(1+\beta)}+\frac{\sigma-\sigma_{s}}{\eta} t & \sigma \geq \sigma_{s} \quad 0<\beta<1\end{cases}
$$

\section{Result Analysis and Discussion}

\subsection{Creep properties of loess}

Test data in staged loading test were organized and analyzed by the Boltzmann overlapping principle, getting the creep curves in different stages under different deviatoric stresses and different moisture contents (Fig. 4-Fig. 5).

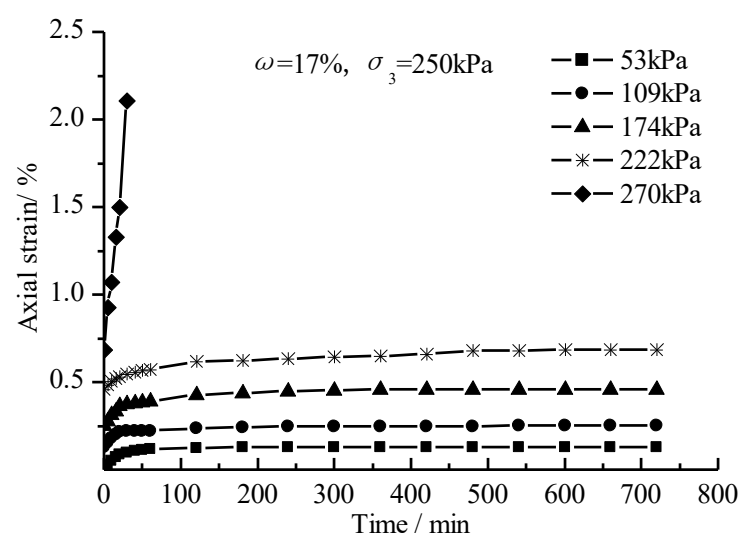

(b) $\omega=17 \%$ 
Fig. 4 shows that loess presents two deformation modes under the constant deviatoric stress. When the deviatoric stress is smaller than the critical stress threshold, axial strain of loess is manifested as the pattern of instantaneous deformation, decelerated creeping and deformation constant. When deviatoric stress is larger than critical stress threshold, axial strain of loess is manifested as the pattern of instantaneous deformation, decelerated creeping and steady creep or instantaneous deformation and accelerated deformation. These two deformation modes reflect that loess has relatively strong stress critical characteristics. When deviatoric stress is relatively small, the non-yield plasticity in loess can finish responses to the stress. In this case, nonfailure deformation is realized in loess through fissure closure, skeletal compression and mutual occlusion of particles. When deviatoric stress exceeds the critical stress, injuries are initiated in loess and cracks develop and expand as the internal shearing or swelling tension exceeds the strength limit of materials. Finally, macrofailure after accelerated deformation is developed.

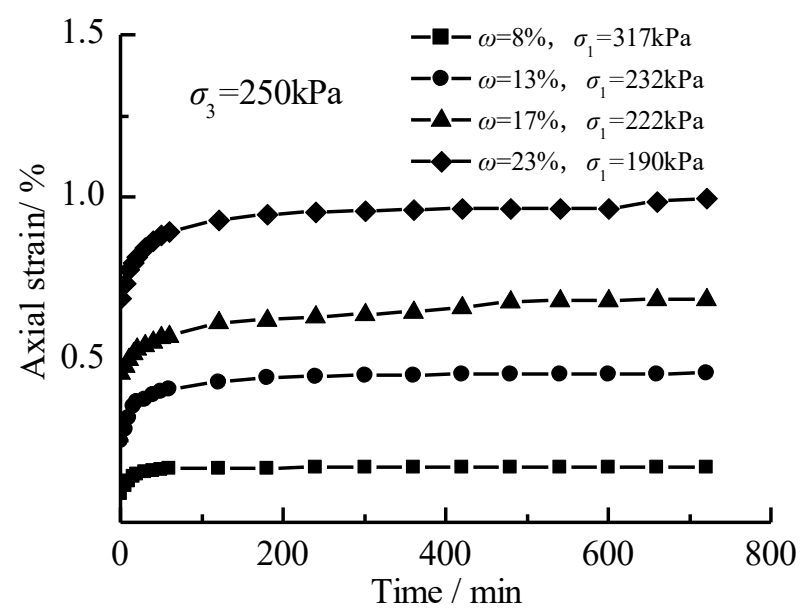

Fig. 5. Strain-time curve of loess with different moisture contents

Influences of water in creep behavior of loess are shown in Fig. 5. As moisture content of loess increases, the axial strain is kept increasing even though the axial loading stress declines within a certain range. This can reflect that the participation of water increases the creep deformation ability of loess. Water body has strong ability in loess softening or decreasing loess resistance to deformation. Water in loess not only can decrease the undisturbed cementation degree of loess, but also can increase the lubrication of interfaces of soil particles, thus intensifying deformation of loess.

\subsection{Loess deformation parameters}

Generally speaking, instantaneous deformation of materials can be simplified as the instantaneous elastic deformation of the materials in the creep test. Hence, the instantaneous deformation is classified into an elastic deformation state in the loess creep test. The elastic parameter $\left(E_{H}\right)$ of loess under different moisture contents is calculated by analyzing the instantaneous stress and strain data (Table 1).

Table 1. $E_{H}$ value of loess under different moisture contents $(\mathrm{kPa})$

\begin{tabular}{l|l|l|l|l}
\hline $\begin{array}{l}\text { Confining } \\
\text { pressure } \\
\text { kPa }\end{array}$ & \multicolumn{4}{|l}{ Moisture content } \\
\cline { 4 - 5 } & $\mathbf{8 \%}$ & $13 \%$ & $17 \%$ & $23 \%$ \\
\hline
\end{tabular}

250

246865

64484

42248

42217

A mathematical regression analysis can be carried out through the relation data between $E_{H}$ and moisture content of loess. It concludes that the relationship between and moisture content of loess can be described by an exponential function. The regression results are shown in Table 2. The comparison between the $E_{H}$-moisture content relation curve of loess under the confining pressure of $250 \mathrm{kPa}$ and the theoretical fitting curve is shown in Fig. 6. Obviously, $E_{H}$ decreases with the increase of moisture content. Moreover, $E_{H}$ drops sharply when the moisture content increases from $8 \%$ to $17 \%$. With the continuous increase of moisture content, $E_{H}$ decreases slowly. It can be speculated that there's certain water volume interval for loess softening after meeting water. Variation of water volume in this interval might cause mutation of mechanical properties of loess.

Table 2. Relations between $E_{H}$ and moisture content of loess

\begin{tabular}{l|l|l}
\hline$\sigma_{3} / \mathbf{k P a}$ & Relations & $\boldsymbol{R}$ \\
\hline 250 & $E_{H}=1395709 \exp (-21.828 \omega)$ & 0.981 \\
\hline
\end{tabular}

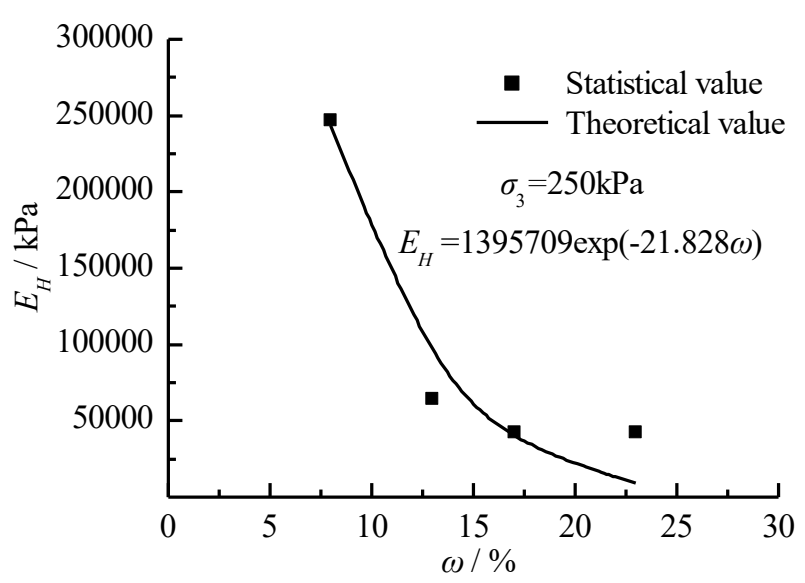

Fig. 6. Relation curve between $E_{H}$ and moisture contents of loess

Based on above analysis on creep properties, loess presents viscoelastic characteristics of creep behaviors when the loading stress is smaller than its critical stress. The isochronal stress-strain curve of loess under different moisture contents and a high confining pressure is gained by further processing above creep test results (Fig. 7). Given the same loading stress, the curve deviates to the strain axis as time goes on, while the axial strain of loess increases gradually, indicating that creep strain increases with time. When the loess is at an inflection point of deviatoric stress, the stress-strain curve is changed from the initial straight into arc, indicating that deviatoric stress at the inflection point is the critical stress for creep yielding of loess. Bordered at the deviatoric stress of the inflection point, the straight section of the stress-strain curve shows viscoelasticity of loess, while the arc section reflects viscoplasticity of loess. 


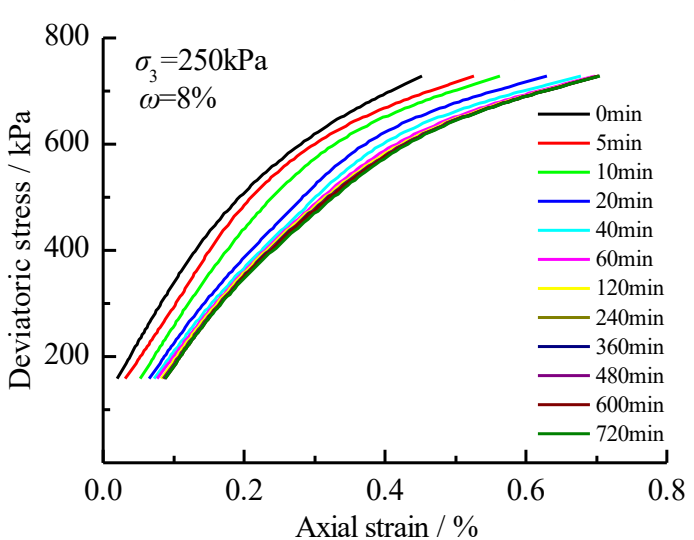

(a) $\omega=8 \%$

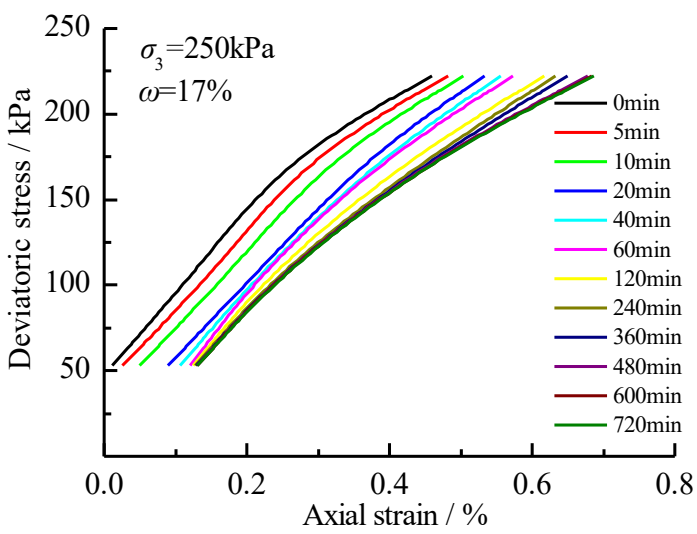

(c) $\omega=17 \%$

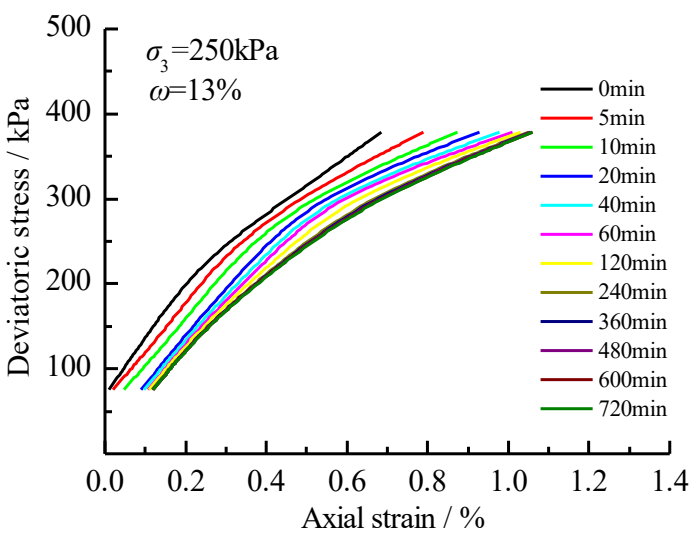

(b) $\omega=13 \%$

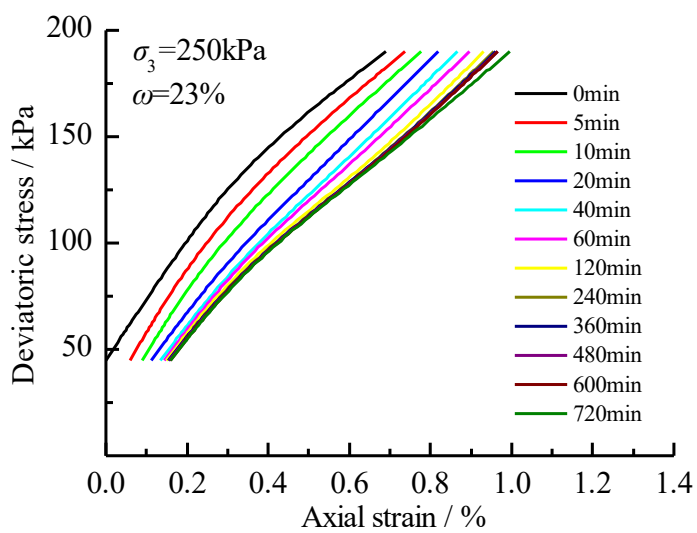

(d) $\omega=23 \%$

Fig. 7. Isochronal stress-strain curve of samples under different moisture contents

The modulus of creep viscoelasticity of loess is approximately defined as the slope of the straight section of isochronal stress-strain curve. Slopes of the approximate straight sections at different moments under different moisture contents in Fig. 6 are calculated and counted, thus getting the approximate modulus of creep viscoelasticity of loess. A regression analysis on the relation curve between modulus of viscoelasticity and moisture content at different moments was carried out based on Eq. (7). Results are shown in Table 3. On this basis, viscoelasticity of loess basically presents a negative exponential reduction with the increase of moisture content at different moments.

$$
E_{(\omega)}=A \exp (-B \omega)
$$

Table. 3. Fitting results of parameters $A$ and $B$

\begin{tabular}{c|c|c|c}
\hline Moments / min & $\boldsymbol{A}$ & $\boldsymbol{B}$ & $\boldsymbol{R}$ \\
\hline 5 & 865.759 & 19.139 & 0.978 \\
10 & 1104.533 & 21.026 & 0.982 \\
20 & 852.298 & 18.888 & 0.988 \\
40 & 712.620 & 17.358 & 0.984 \\
60 & 647.995 & 16.318 & 0.977 \\
120 & 782.136 & 17.966 & 0.982 \\
240 & 823.041 & 18.474 & 0.986 \\
360 & 832.635 & 18.611 & 0.986 \\
480 & 832.635 & 18.611 & 0.986 \\
600 & 835.083 & 18.647 & 0.986 \\
720 & 840.472 & 18.728 & 0.986 \\
Mean & 829.928 & 18.524 & - \\
\hline
\end{tabular}

\subsection{The improved four-element model of loess}

\subsubsection{Nonlinear viscoplasticity model}

In the element model, many scholars have constructed binary structural models through parallel connection of viscous element and ideal plastomer to describe viscoplasticity of materials. However, these models cannot reflect nonlinear rheological characteristics of materials since the viscous elements are linear ones with constant parameters, which is a performance defect. To solve this problem, many scholars have proposed to improve constant parameters of viscous elements into variable ones, so that the improved viscous elements can cover variation laws of other influencing factors, including time, stress, water and temperature. Based on this idea, a nonlinear viscous element which considers influences of moisture content is proposed by the accelerated creep curve fitting of loess combined with analogy. It is connected with the ideal plastic element in parallel by the stress triggering mode and a viscoplasticity model that can describe nonlinear accelerate creep properties of loess is constructed.

The accelerated creep curves of loess samples with different moisture contents under a high confining pressure are fit through a functional equation that combines power function and exponential function:

$$
\varepsilon=\varepsilon_{0}+C\left(t^{n}+e^{n t}\right)
$$

where $\varepsilon$ is the model strain, $\varepsilon_{0}$ is strain value before the accelerated creep and $C$ is the fitting parameters and it represents the historical parameters of stress. Besides, $t$ is the creep time and $n$ is the accelerated creep parameter.

The comparison between the curve section of accelerated creep (Eq. (8)) and the theoretical curve is shown in Fig. 8. The corresponding parameter fitting results are shown in Table 4 


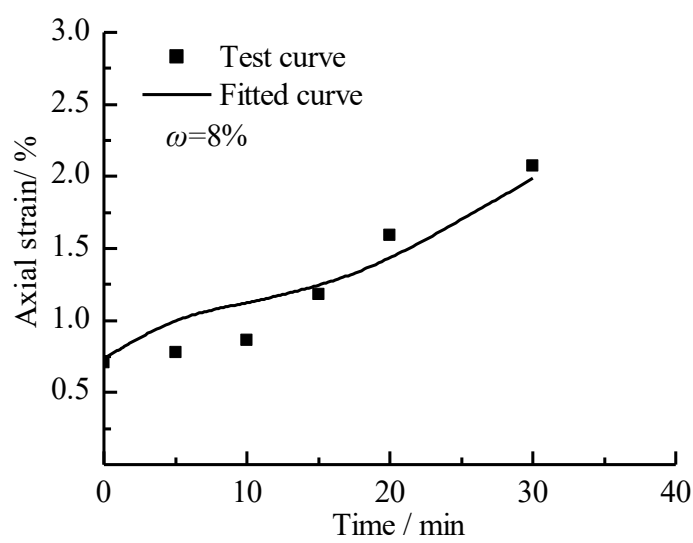

(a) $\omega=8 \%$

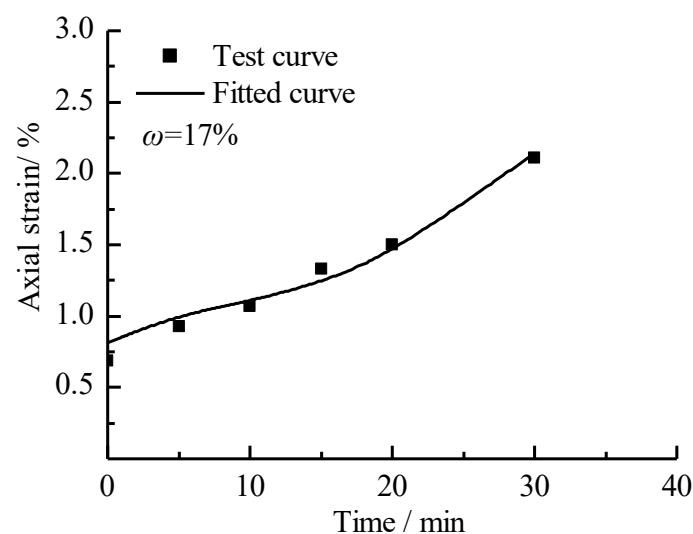

(c) $\omega=17 \%$

Fig. 8. Accelerated creep test curve of loess and theoretical curve

Table 4. Fitting results of parameters in Eq. (8)

\begin{tabular}{l|l|l|l|l}
\hline Moisture content & $\varepsilon_{0}$ & $\boldsymbol{C}$ & $\boldsymbol{n}$ & $\boldsymbol{R}$ \\
\hline $8 \%$ & 0.705 & 0.129 & 0.072 & 0.969 \\
$13 \%$ & 1.060 & 0.132 & 0.077 & 0.969 \\
$17 \%$ & 0.687 & 0.124 & 0.079 & 0.987 \\
$23 \%$ & 0.988 & 0.073 & 0.102 & 0.982 \\
\hline
\end{tabular}

Variations of different parameters in Table 4 with moisture content were analyzed. All parameters (e.g. $\varepsilon_{0}$ and $C$ ) except $n$ have no obvious relations with moisture content. The parameter generally is positively related with the moisture content. The variation of $n$ with moisture content is shown in Fig. 9. The variation trend characteristics are observed and fitting analysis is carried out based on Eq. (9):

$n=d \omega^{5}+f$

The corresponding fitting parameters $d$ and $f$ are 44.547 and 0.073 , respectively. The correlation coefficient of parameter fitting is 0.994 .

Suppose the moisture content is 0 and the accelerated creep parameter is $n_{0}$. Bring $\omega=0$ into the Eq. (9) and it gets $n=f=n_{0}$.

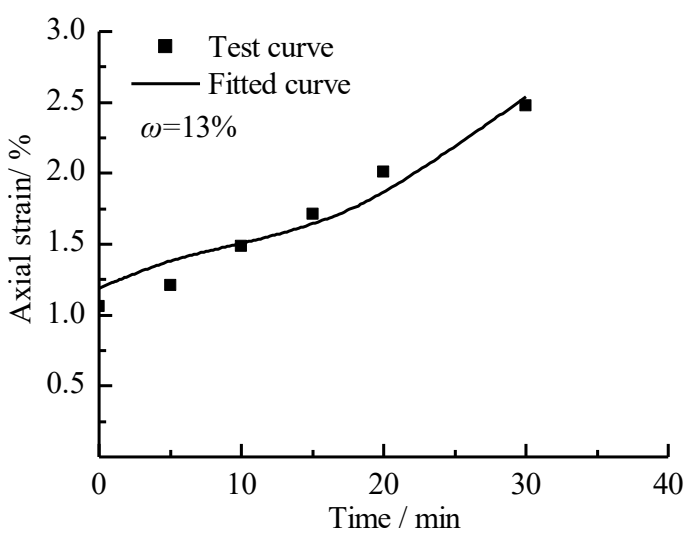

(b) $\omega=13 \%$

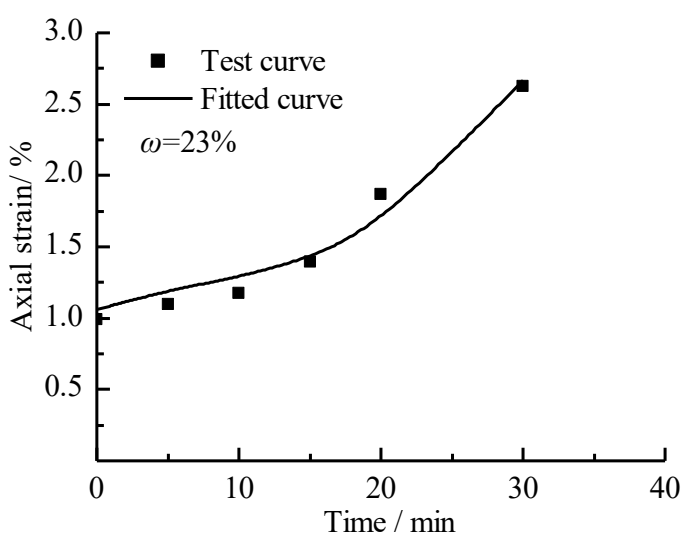

(d) $\omega=23 \%$

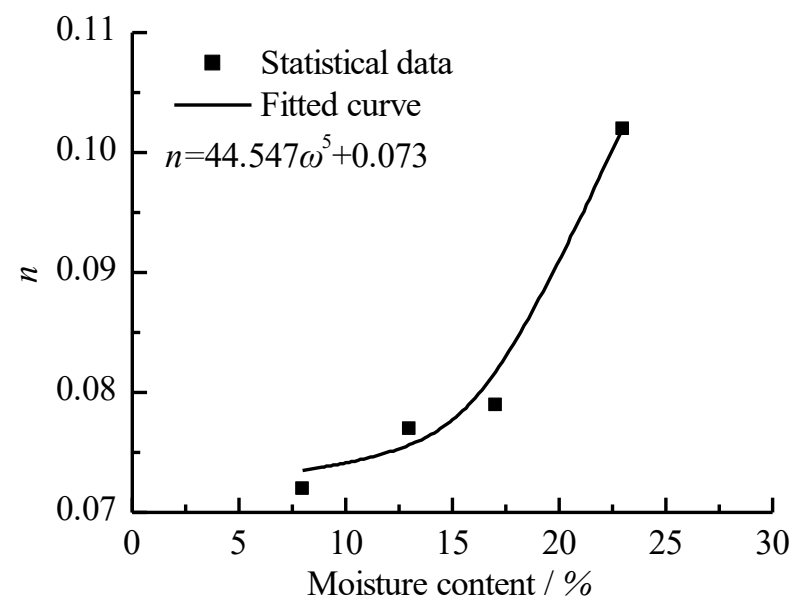

Fig. 9. Distribution of $n$ values and fitting curves

$n=d \omega^{5}+n_{0}$

where $n_{0}$ is the accelerated creep parameter when the loess is at the drying state.

The Eq. (10) is brought into the Eq. (8) to get the function expression of axial strain in the accelerated creep stage of loess with time and moisture content:

$\varepsilon=\varepsilon_{0}+C\left(t^{d \omega^{5}+n_{0}}+e^{d \omega^{5} t+n_{0} t}\right)$ 
For the viscoplasticity section in the model in Fig.6, when the stress is higher than the yield stress, the creep equation can be expressed as:

$$
\varepsilon=\frac{\left(\sigma-\sigma_{s}\right) t}{\eta}+D
$$

where $\sigma_{s}$ is the yield stress and $D$ is the integral constant. Comparing Eq. (11) and Eq. (12), taking $C=\frac{\left(\sigma-\sigma_{s}\right)}{\eta_{0}}$ and $D=\varepsilon_{0}$, the expression of the parameter $(\eta)$ of the nonlinear viscous element is:

$$
\eta=\frac{\eta_{0} t}{t^{d \omega^{5}+n_{0}}+e^{\left(d \omega^{5}+n_{0}\right) t}}
$$

where $\eta_{0}$ is the initial viscous coefficient of accelerated creep.

Based on above fitting analysis of accelerated creep curve of loess, the improved nonlinear viscoplasticity model is gained through analogy (Fig. 10).

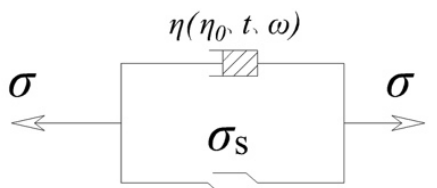

Fig. 10. Nonlinear viscoplasticity model

$$
\left\{\begin{array}{l}
\varepsilon=\frac{\sigma}{E_{H}}+\frac{\sigma}{\xi} \cdot \frac{t^{\beta}}{\Gamma(1+\beta)} \quad \sigma<\sigma_{s} \quad 0<\beta<1 \\
\varepsilon=\frac{\sigma}{E_{H}}+\frac{\sigma}{\xi} \cdot \frac{t^{\beta}}{\Gamma(1+\beta)}+\frac{\sigma-\sigma_{s}}{\eta_{0}}\left[t^{d \omega^{5}+n_{0}}+e^{\left(d \omega^{5}+n_{0}\right) t}\right] \quad \sigma \geq \sigma_{s} \quad 0<\beta<1
\end{array}\right.
$$

\subsection{Verification of the model}

According to creep test results of loess with different moisture contents under a high confining pressure, parameters of the above improved four-element model of loess were recognized by using the 1 stOpt mathematical optimization analysis software to verify the consistency of model with test results and judge applicability of the model.

The creep test curve of loess with $8 \%$ under $250 \mathrm{kPa}$ is taken for example. The curve is fit according to the Eq. (15) and relevant parameters are gained (Table 5). The comparison between corresponding test curve and theoretical curve of the model is shown in Fig. 12. It can be seen from comparison between the correlation coefficient of model parameter fitting and curve that the test curve agrees highly with the theoretical curve and the model has good fitting degree to the curves. This indicates that the improved four-element model of loess not only can reflect nonlinear creep properties of aquiferous loess under a high confining pressure, but also characterizes accuracy and applicability of the model.
The nonlinear viscoplasticity model not only can reflect viscoplasticity creep of loess materials under different time states, but also can consider influences of water on creep. The creep equation of model is:

$$
\varepsilon(t)=\frac{\sigma-\sigma_{s}}{\eta_{0}}\left[t^{d \omega^{5}+n_{0}}+e^{\left(d \omega^{5}+n_{0}\right) t}\right]
$$

\subsubsection{Improvement of model}

Based on above analysis of viscoplasticity feature of loess with different moisture content, the nonlinear viscoplasticity model in Fig. 9 is improved based on the four-element model in Fig. 7. A nonlinear four-element model of accelerated creep properties of loess which can reflect influences of moisture content can be constructed. The model structure is shown in Fig.11. The creep equation of the model is shown in Eq. (15).

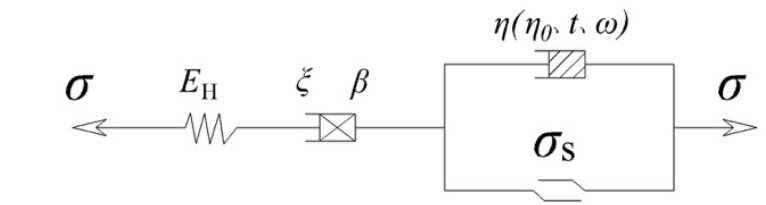

Fig. 11. Nonlinear four-element model of loess

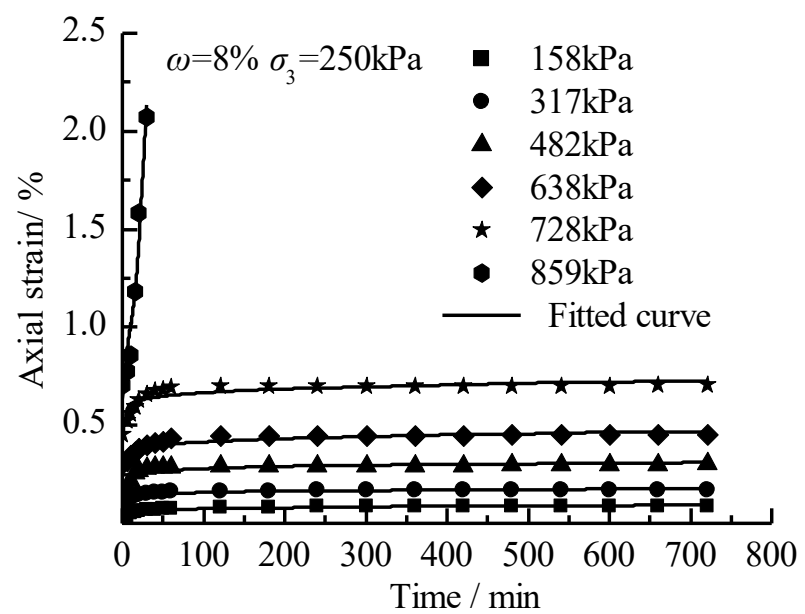

Fig. 12. Test curve and theoretical curve

Table 5. Parameters of model

\begin{tabular}{c|c|c|c|c|c}
\hline Stress / kPa & $E_{H} / \mathbf{M P a}$ & $\xi /\left(\mathbf{M P a} \cdot \mathbf{m i n}^{\beta}\right)$ & $\beta$ & $\eta_{0} /(\mathbf{M P a} \cdot \mathbf{m i n})$ & $\boldsymbol{R}$ \\
\hline 158 & 2375.775 & 431.266 & 0.121 & - & 0.948 \\
317 & 371.920 & 801.684 & 0.119 & - & 0.937 \\
482 & 301.037 & 726.658 & 0.115 & - & 0.881 \\
638 & 214.832 & 1365.154 & 0.186 & - & 0.924 \\
728 & 163.589 & 623.855 & 0.125 & 97.513 & 0.914 \\
859 & 182.166 & 2824299.067 & 0.122 & 0.970 \\
\hline
\end{tabular}




\section{Conclusions}

An appropriate creep constitutive model is constructed to analyze creep properties of aquiferous loess under a high confining pressure. In this study, a triaxial creep test of loess with different moisture contents under a high confining pressure is carried out based on a loess slope. The influencing laws of moisture content on elasticity and viscoelasticity of loess are analyzed. On this basis, a model to describe creep properties of loess is constructed. Some major conclusions could be drawn from above analysis:

Water can soften loess significantly. increasing moisture content can enhance effects of creep deformation of loess.

Elastic deformation and viscoelastic deformation of loess weaken with the increase of moisture content. The corresponding relations of instantaneous modulus of elasticity and modulus of viscoelasticity with moisture content can be described by a negative exponential function.

The nonlinear viscoplasticity model which is constructed by the fitting analog can describe the accelerated creep segment of loess $Q_{2}$. On this basis, the improved four- element model can describe the overall creep properties of loess effectively.

The study results can provide some experiences to understand creep properties of loess and further analysis on slope stability. However, slope instability is the collaborative consequence of multiple factors. In this study, the proposed model to describe creep properties of loess considers influences of moisture content only. In future studies, other influencing factors of slope stability can be introduced into the model to expand its application range, which can provide more assistance to understand the creep behaviors of slope under complicated stress states.

\section{Acknowledgements}

The authors gratefully acknowledge the support of the National Natural Science Foundation of China (Grant No. 41602305).

This is an Open Access article distributed under the terms of the Creative Commons Attribution License.

\section{References}

1. Fernandes, R. R., Wilson, D. I., "Modelling the cleaning of viscoplastic layers by impinging coherent turbulent water jets". Journal of Non-Newtonian Fluid Mechanics, 282, 2020, pp.104314.

2. Montero-Cubillo, N. S., Galindo-Aires, R. A., Serrano-Gonzalez, A., Olalla-Maranon, C., Simic-Sureda, F. D., "Analytical model of an anchored wall in creep soils". International Journal of Geomechanics, 20(4), 2020, pp.04020027.

3. Deng, H. Y., Dai, G. L., Azadi, M. R., "Fractional time-dependent merchant model for coastal soft clay". Journal of Coastal Research, 104(SI), 2020, pp.825-831.

4. Zhang, D., Liu, E. L., Huang, J., "Elastoplastic constitutive model for frozen sands based on framework of homogenization theory". Acta Geotechnica, 15(7), 2020, pp.1831-1845.

5. Pramthawee, P., Jongpradist, P., Sukkarak, R., "Integration of creep into a modified hardening soil model for time-dependent analysis of a high rockfill dam". Computers and Geotechnics, 91, 2017, pp.104-116.

6. Wang, L. Y., Zhou, F. X., "Fractional derivative in the elasticviscoplastic stress-strain state model describing anisotropic creep of soft clays". Mechanics of Time-Dependent Materials, 2020.

7. Wang, X. G., Wang, J. D., Zhan, H. B., Li, P., Qiu, H. J., Hu, S., "Moisture content effect on the creep behavior of loess for the catastrophic Baqiao landslide". Catena, 187, 2020, pp.104371.

8. Wang, Y. F., Cai, Z.Y., Cai, Y. Y., Guan, Y. F., "Comparative studies of creep characteristics of saturated soils at drained $k_{0}$ consolidation". Journal of Basic Science and Engineering, 25(5), 2017, pp.985-997.

9. Sun, M. J., Tang, H. M., Wang, X. H., Hu, X. L., Wang, M. Y. Ni, W. D., "Creep properties of sliding-zone soil from a creeping landslide". Rock and Soil Mechanics, 38(2), 2017, pp.385-391,399.

10. Kamoun, J., Bouassida, M., "Creep behavior of unsaturated cohesive soils subjected to various stress levels". Arabian Journal of Geosciences, 11(4), 2018, pp.77.

11. Liu, J. S., Jing, H. W., Meng, B., Wang, L. G., Yang, J. J., You, Y. W., Zhang, S. J., "Fractional-order creep model for soft clay under true triaxial stress conditions". Arabian Journal of Geosciences, 13(17), 2020, pp.834.

12. Xue, K. X., Wang, S. F., Hu, Y. X., Li, M. D., "Creep behavior of red-clay under triaxial compression condition". Frontiers in Earth Science, 7, 2020, pp.345.

13. Liu, M. C., Wang, Z. X., Wang, Y. Y., "Constitutive modeling of creep behaviors of coarse-grained materials". Chinese Journal of Geotechnical Engineering. 42(6), 2020, pp.1108-1114.

14. Guo, H., Luo, Y. S., Hu, L. X., Wang, P. C., "Plane creep model of loess". Acta Scientiarum Naturalium Universitatis Sunyatseni, 56(6), 2017, pp.94-99.
15. Shahbodagh, B., Mac, T. N., Esgandani, G. A., Khalili, N., "A Bounding surface viscoplasticity model for time-dependent behavior of soils including primary and tertiary creep". International Journal of Geomechanics, 20(9), 2020, pp. 04020143.

16. Tafili, M., Triantafyllidis, T., "A simple hypoplastic model with loading surface accounting for viscous and fabric effects of clays". International Journal for Numerical and Analytical Methods in Geomechanics, 44(16), 2020, pp.2189-2215.

17. Gras, J. P., Sivasithamparam, N., Karstunen, M., Dijkstra, J., "Permissible range of model parameters for natural fine-grained materials". Acta Geotech, 13, 2018, pp.387-398.

18. Islam, M. N., Gnanendran, C. T., "Elastic-viscoplastic model for clays: Development, validation, and application". Journal of Engineering Mechanics, 143 (10), 2017, pp.04017121.

19. Jin, J. C., She, C. X., Shang, P. Y., "A nonlinear creep model of rock based on the strain softening index". Rock and Soil Mechanics, 40(6), 2019, pp.2239-2246, 2256.

20. Kavvadas, M., Kalos, A., "A time-dependent plasticity model for structured soils (TMS) simulating drained tertiary creep". Computers and Geotechnics, 109, 2019, pp.130-143.

21. Oliveira, P. J. V., Santos, S. L., Correia, A., Lemos, L., "Numerical prediction of the creep behaviour of an embankment built on soft soils subjected to preloading". Computers and Geotechnics, 114, 2019, pp.103140.

22. Yuan, Y., Liu, R., Qiu, C. L., Tan, R. J., "Establishment and application of creep constitutive model related to stress level of soft soil". Journal of Tianjin University (Science and Technology), 51(7), 2018, pp.711-719.

23. Yin, D. S., Ren, J. J., He, C. L., Chen, W., "A new rheological model element for geomaterials". Chines Journal of Rock Mechanics and Engineering, (09), 2007, pp.1899-1903.

24. Yin, D. S., He, C. L., Chen, W., "Theory of geotechnical strain hardening index and its rationale from fractional order calculus". Chinese Journal of Geotechnical Engineering, 32(5), 2010, pp.762766.

25. Ding, J. Y., Zhou, H. W., Li, C., Wang, C. P., Wu, Z. D., "The fractional derivative approach to creep constitutive model of salt rock based on Weibull distribution". Chinese Journal of Solid Mechanics, 34(5), 2013, pp.473-479.

26. Zhou, H. W., Wang, C. P, Duan, Z. Q., Zhang, M., Liu, J. F., "Time-based fractional derivative approach to creep constitutive model of salt rock". Scientia Sinica Physica, Mechanica and Astronomica, 42(3), 2012, pp.310-318.

27. Song, Y. J., Lei, S. Y., "Mechanical model of rock nonlinear creep damage based on fractional calculus". Chines Journal of Underground Space and Engineering, 9(1), 2013, pp.91-95. 
Renhong Ding, Hao Tang, Zhao Duan, Yanqing Zhang and Hongjun Jing/

Journal of Engineering Science and Technology Review 14 (3) (2021) 59 - 68

28. Chen, J. H., Yao, Z. M., Xu, Y., Wang, H. L., "Particle swarm fractional order derivative model of artificial frozen soil creep properties". Journal of China Coal Society, 38(10), 2013, pp.17631767.
29. Chen, L., Chen, S. G., Zhang, H., Yang, J. S., "A new viscoelastoplastic creep model based on fractional calculus". Journal of Sichuan University (Engineering Science Edition), 45(3), 2013, pp.7-11. 